\title{
Dietary prevention of coronary heart disease. Effect of dietary fats on arterial thrombosis
}

\author{
GERARD HORNSTRA \\ M.D. \\ Department of Biochemistry, Biomedical Centre, State University of Limburg, Maastricht, The Netherlands
}

\begin{abstract}
Summary
Epidemiological studies indicate that dietary saturated fats are implicated in coronary heart disease (CHD). Human prospective studies have shown that diets low in long chain saturated fatty acids and enriched in linoleic acid are beneficial in CHD-prevention. Experiments in animals have shown that such diets diminish atherosclerosis and the tendency to arterial thrombosis; they also lower the ability of platelets to aggregate in animals and in man. The mechanisms by which these diets produce these effects are not yet completely understood. Platelet and vascular prostaglandin-like substances may be involved as well as platelet membrane fluidity and platelet coagulant activities. On the basis of the available evidence, measures to decrease the intake of long chain saturated fatty acids (concomitant with an enhanced consumption of linoleic acid-rich products) are justified. Although certain marine oils may also have anti-thrombotic properties the possibility of undesirable side effects compels extensive investigation before their widespread use can be recommended.
\end{abstract}

\section{Introduction}

Mortality profiles show that, in most cases, after the onset of acute myocardial infarction there is too little time for successful intervention and secondary prevention. Therefore, special emphasis on primary prevention of coronary heart disease (CHD) is indicated.

CHD generally results from atherosclerosis of the coronary arteries. There is now general agreement on the view that type and amount of dietary fat can influence the genesis and course of experimental atherosclerosis (Gottenbos and Thomasson, 1961 ; Vles et al., 1964; Malmros, 1969). Since atherosclerosis is a multifactorial disease (Wolf, 1971) these fat effects can be mediated by different pathways. Arterial thrombosis is the main lethal complication of atherosclerosis (Owren, 1964; Harland and Holburn, 1966; Haerem, 1974; Sinapius, 1972).

Correspondence: G. Hornstra, Department of Biochemistry, Biomedical Centre, State University of Limburg, P.O. Box 616, 6200 MD Maastricht, The Netherlands.
Moreover, it has been shown that mural arterial thrombi become incorporated into the arterial wall (Duguid, 1946; Sumiyoshi, More and Weigensberg, 1973; Moore, 1974), thereby contributing to the development of the atherosclerotic plaque.

Role of blood platelets in arterial thrombosis and atherosclerosis

Basically, arterial thrombosis depends upon 2 factors: vascular injury and the response of circulating blood towards this injury (Fig. 1). As a

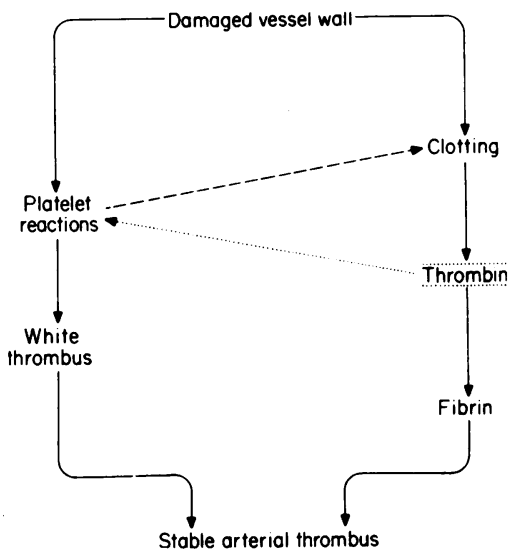

Fig. 1. Simplified diagram of arterial thrombus formation.

result of vascular damage, blood inside the vessel is no longer protected from contact with subendothelial structures. This subendothelium is highly 'attractive' for blood platelets, which readily adhere to it and, thereby, become activated to produce and release substances that cause passing platelets to aggregate with the adhered ones. The newly aggregated platelets become activated as well and initiate a self-propagating process of aggregation and activation. These platelet reactions lead to the formation of a fragile platelet mass, the so-called white thrombus (Mustard and Packham, 1970). Vascular damage also initiates blood clotting. This clotting response is enhanced by activated blood platelets and 
the fibrin formed reinforces the fragile platelet mass to a stabilized thrombus of great pathological significance. There is evidence that thrombin, generated as a result of vessel wall-induced clotting, is of key importance in white thrombus formation, as its local presence has been shown to be essential for platelet aggregation induced by damaged vascular tissue (Hornstra and Hemker, 1979).

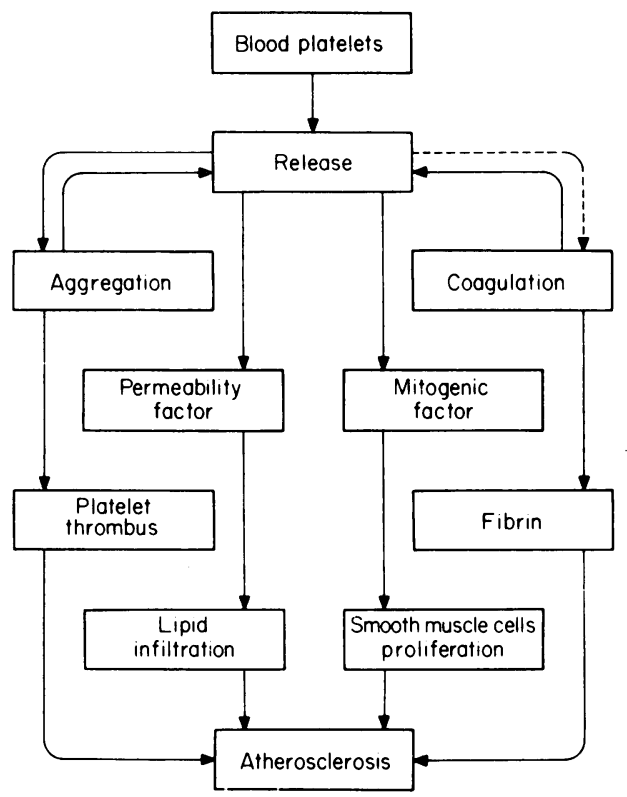

FIG. 2. Role of blood platelets in atherogenesis.

There are 2 other ways in which blood platelets participate in atherogenesis (Fig. 2). Upon their activation they also release a so-called mitogenic factor that stimulates the proliferation of medial smooth muscle cells (Ross et al., 1974), and their migration into the mural thrombus. These processes are considered of key importance in the formation of advanced atherosclerotic lesions (Ross and Glomset, 1976). Moreover, activated platelets release serotonin, which induces endothelial contraction and facilitates lipid infiltration into the arterial wall as well as thrombus formation (Shimamoto, 1974). In experimental animals, a key role of platelets in atherogenesis has been demonstrated very convincingly (Harker et al., 1976; Moore et al., 1976; Friedman et al., 1977; Fuster and Bowie, 1978), which implies that decreasing the platelet activation level and lowering the arterial thrombosis tendency will be beneficial in the prevention of atherosclerosis and its complications.

\section{Animal experiments}

Because of the connection between arterial throm- bosis and atherosclerosis, it is of interest to know whether dietary fats are able to modify arterial thrombosis tendency and its underlying processes. Therefore experiments were started, using a newly developed model for occlusive arterial thrombosis, based on the insertion of a loop-shaped polyethylene cannula into the abdominal aorta of male rats. At places where the cannula was in permanent contact with the vessel wall, endothelial damage and flow disturbances resulted in the production and growth of a fibrin-poor, platelet-rich thrombus which reached an occlusive state after about 5 days. This moment of total obstruction was indicated by a change in colour of the blood in the translucent loop which projected from the body. The period between insertion and complete obstruction is called the obstruction time (OT) and is a measure of the arterial thrombosis tendency: the shorter the OT, the higher the arterial thrombosis tendency. The usefulness of this arterial thrombosis model was adequately demonstrated by the observed OTincreasing effect of anti-thrombotic drugs such as aspirin, heparin and prostaglandin $\mathrm{E}_{1}$ (Hornstra and Vendelmans-Starrenburg, 1973; Hornstra, 1973/ 74). Using this model it appeared that dietary saturated fatty acids which contain 14 or more carbon atoms promote arterial thrombosis. Monoe unsaturated fatty acids are neutral in this respect and decrease arterial thrombosis tendency only if the replace long chain saturated fatty acids. Linoleic acid and, most probably, linolenic acid as well, inhibits arterial thrombus formation (Hornstra and Lussenburg, 1975).

\section{Human studies}

Although these experimental results have been confirmed by many other investigators using a great variety of animal models (Renaud and Gautheron, 1973/74; Hornstra, 1973/74), it is not justifiable to extrapolate these animal data to the human situation. The maximum benefit from all animal data is that they may form a guideline for human studies and consequently it is especially worthwhile to investigate whether also in man replacement of saturated fats by linoleic acid-rich oils has an anti-thrombotic and anti-atherosclerotic effect. From epidemiological studies this seems likely $N$ because the intake of saturated fat is still the environmental factor the most closely associated with coronary heart disease (Stamler, 1973; Heyden, 1975).

The value of epidemiological studies, however, is rather limited as they only detect associations 0 but are not suitable to prove cause-and-effect $\overparen{\unrhd}$ relationships. For this latter purpose, prospective $\stackrel{\oplus}{?}$ clinical trials are needed, several of which have now been completed, all indicating a favourable effect of a diet low in saturated fats and enriched in 
linoleic acid (Leren, 1966; Dayton et al., 1969; Miettinen et al. (1972)). The beneficial effects of these diets are not necessarily the result of their plasma lipid-lowering action only, but may be mediated by their effect on platelet thrombotic functions as well.

In this respect, recent results of Renaud et al. (1979) are of extreme interest. They selected 2 regions in France and 2 in Scotland with marked differences in mortality from CHD. Here they surveyed the diet, determined the classical risk factors (blood lipids, blood pressure, smoking habits, etc.) and, moreover, performed tests for platelet reactivity. It then appeared that there were no differences in blood lipid levels between the high- and low-risk regions, although the saturated fat intake differed significantly. Blood platelets, on the other hand, appeared to be hyperactive in the high risk group, especially as far as their participation in blood clotting and aggregation in response to thrombin is concerned. In fact, these platelet functions appeared to be the only blood parameters related to the incidence of CHD in these regions.

A contribution of thrombotic platelet functions to mortality from CHD is also suggested from aggregation studies performed at the end of the Helsinki primary prevention trial (Miettinen et al., 1972). This study was conducted in 2 mental hospitals ( $\mathrm{K}$ and $\mathrm{N}$ ). In the control hospital (N) the normal Finnish diet, which is rich in saturated fats and contains only $4 \%$ of its digestible energy as linoleic acid, was given all the time. In the other hospital (K), the diet was modified: milk was replaced by soy-bean oil-filled skim milk whereas butter and ordinary margarines were replaced by so-called 'soft' margarines, resulting in a dietary linoleic acid content of $12 \%$ energy. After 6 years the diets were reversed, the total experimental period being 12 years. Then it appeared that in men, but not in women, the high linoleic acid diet was associated with a $50 \%$ reduction in mortality from CHD. At the end of the second 6-year period the opportunity occurred to measure the platelet aggregation which, in the rat studies, had been shown to correlate well with the arterial thrombosis tendency (Hornstra and Lussenburg, 1975). Measurements were carried out with a newly developed device, the filtragometer (Hornstra and ten Hoor, 1975). Blood from a forearm vein is drawn through a microfilter at a constant rate of $2 \mathrm{ml} / \mathrm{min}$. Blood pressures are measured at both sides of the filter, and the difference $(\Delta P)$ is recorded continuously. The blood is anticoagulated with heparin. When platelets present in the blood aggregate and obstruct the filter, the pressure difference across the filter changes. This is indicated by a rise in the $\Delta \mathrm{P}$-curve. At a $\Delta \mathbf{P}$-value of $5 \mathrm{mmHg}$, heparin is replaced by sodium citrate. This lowers the free calcium content of the blood and so results in dispersion of the aggregation on the filter. Consequently, $\Delta \mathrm{P}$ decreases again. From the $\Delta \mathrm{P}$-curve the various aggregation and de-aggregation parameters are calculated. The filtragometer proved to be a suitable device for monitoring the anti-platelet effects of oral aspirin and of prostaglandin $E_{1}$. Moreover, it appeared that women have a lower platelet aggregation than men. (a)

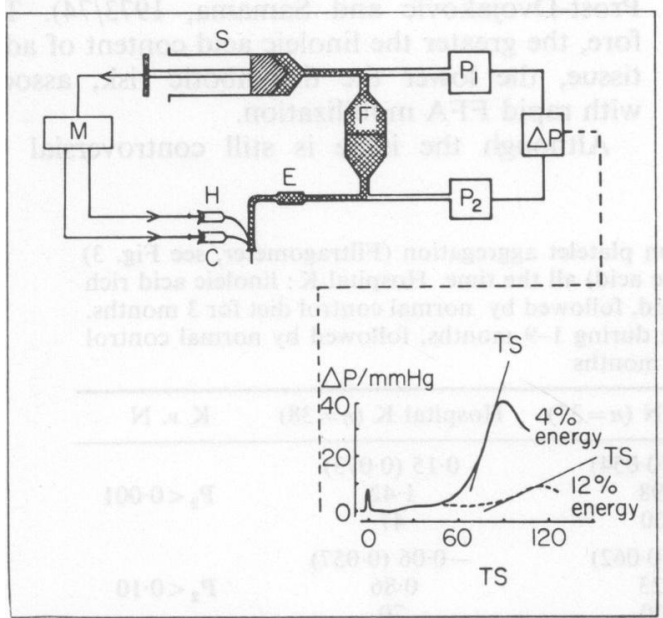

(b)

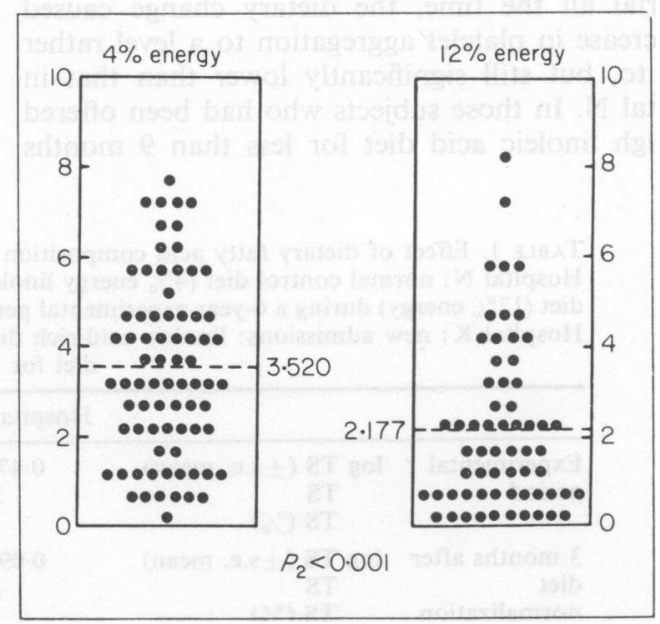

FIG. 3. Effect of long-term replacement of dietary saturated fats by linoleic acid-rich products on platelet aggregation (filtragometer). (a) Diagram of filtragometer and mean aggregation curves. (b) Individual values for maximum aggregation velocity (TS). $C=$ citrate infusion; $E=$ mixing chamber; $F=$ filter; $H=$ heparin infusion; $\mathbf{M}=$ motor $; \mathbf{P}_{1} / \mathbf{P}_{2}=$ pressure before/after; $\triangle \mathbf{P}=\mathbf{P}_{1}-\mathbf{P}_{2} ; \mathbf{S}=$ syringe. 
Subjects with a history of myocardial infarction show an increased filtragometer response. The same applies to people suffering from angina pectoris and diabetes mellitus (Hornstra, 1978).

As is shown in Fig. 3, the filtragometer response is definitely lower in the high linoleic acid group than in the control group. Since mortality from CHD is often associated with occlusive coronary thrombosis-in which platelet aggregation is involved-it is highly probable that the low platelet aggregation in the high linoleic acid group, contributed to the lower mortality (Hornstra et al., 1973). As stated before, the Helsinki primary prevention trial was carried out in 2 different hospitals using a cross-over design. During the second 6year period, hospital $\mathrm{K}$ was given the experimental diet whereas in hospital $\mathrm{N}$ the normal control diet was provided. After the end of this second period the first aggregation measurements were performed showing a decreased platelet aggregation in the experimental group. Nine months later, the experimental diet was replaced by the normal diet. In the meantime, however, new patients had entered hospital $\mathrm{K}$ who, at the moment of the dietary change, had been on the experimental diet for only a relatively short period. Three months after return to the normal diet in hospital K, platelet aggregation was re-studied in both hospitals. Results are given in Table 1. Owing to a technical modification of the filtragometer device the aggregation values obtained at the second measurement were different from the first values. However, in the control hospital no dietary change had occurred so at both measurements platelet aggregation can be taken as $100 \%$. In those subjects from hospital $\mathbf{K}$ who had been in the trial all the time, the dietary change caused an increase in platelet aggregation to a level rather close to, but still significantly lower than that in hospital N. In those subjects who had been offered the high linoleic acid diet for less than 9 months before they changed to the normal diet, platelet aggregation was not different from that in the control group. This finding strongly suggests that linoleic acid in adipose tissue, which has a much slower turn-over than that in blood lipids (Dayton, 1966; Fleischman, Hayton and Bierenbaum, 1967), in some way has a long-term protective effect after pro-thrombotic dietary changes. The same suggestion was obtained from animal experiments since the arterial thrombosis tendency in rats fed a thrombogenic diet increased more slowly, the longer the animals had been pre-treated with an antithrombotic diet rich in linoleic acid (Hornstra, 1975). Epidemiological findings by Logan et al. (1978) are also of interest in this respect. These workers compared blood and adipose tissue lipid profiles of a sample from the Stockholm and Edinburgh populations and noticed that the higher mortaility from CHD in Edinburgh was associated with a lower linoleic acid content for blood lipid and adipose tissue, whereas total serum and low density lipoprotein cholesterol content appeared to be similar. In the long-term thrombo-protective role of linoleic acid in adipose tissue, plasma FFA composition might be involved.

In stress situations, release of catecholamine causes a rapid mobilization of free fatty acids (FFA) sometimes to such an extent that the FFA-bindin capacity of plasma proteins is exceeded. It has beep. shown very convincingly that this situation causes. hyperaggregation of blood platelets (Hoak, Poole and Robinson, 1963; Connor, Hoak and Warner, 1969). Moreover, it has been shown that these platelet reactions depend on the type of FFA: longchain saturated fatty acids are much more active in this respect than linoleic acid (Hoak et al., 1970; Prost-Dvojakovic and Samama, 1973/74). Therefore, the greater the linoleic acid content of adipose tissue, the lower the thrombotic risk, associated with rapid FFA mobilization.

Although the issue is still controversial (Opie

TABLE 1. Effect of dietary fatty acid composition on platelet aggregation (Filtragometer, see Fig. 3) Hospital N: normal control diet (4\% energy linoleic acid) all the time. Hospital K: linoleic acid rich diet ( $12 \%$ energy) during a 6-year experimental period, followed by normal control diet for 3 months. Hospital K: new admissions: linoleic acid-rich diet during 1-9 months, followed by normal control diet for 3 months

\begin{tabular}{|c|c|c|c|c|}
\hline & & Hospital N $(n=37)$ & Hospital K $(n=38)$ & $\mathrm{K} v \cdot \mathrm{N}$ \\
\hline $\begin{array}{l}\text { Experimental } \\
\text { period }\end{array}$ & $\begin{array}{c}\log \text { TS }( \pm \text { s.e. mean }) \\
\text { TS } \\
\text { TS }(\%)\end{array}$ & $\begin{array}{c}0.47(0.054) \\
2.98 \\
100\end{array}$ & $\begin{array}{c}0.15(0.073) \\
1.42 \\
47\end{array}$ & $P_{2}<0.001$ \\
\hline \multirow[t]{2}{*}{$\begin{array}{l}3 \text { months after } \\
\text { diet } \\
\text { normalization }\end{array}$} & $\begin{array}{c}\log \operatorname{TS}( \pm \text { s.e. mean }) \\
\text { TS } \\
\text { TS }(\%)\end{array}$ & $\begin{array}{c}0.09(0.062) \\
1.23 \\
100\end{array}$ & $\begin{array}{c}-0.06(0.057) \\
0.86 \\
70\end{array}$ & $P_{2}<0 \cdot 10$ \\
\hline & $\begin{array}{c}\log \text { TS } \pm \text { s.e. mean) } \\
\text { TS } \\
\text { TS }(\%)\end{array}$ & new admissions & $\begin{array}{c}0.05(0.067) \\
1.12 \\
91\end{array}$ & $P_{2}>0.10$ \\
\hline
\end{tabular}


et al., 1971; Kostis, et al., 1973), an increase in plasma FFA may also promote cardiac arrhythmias, thereby contributing to myocardial death (Oliver, Kurien and Greenwood, 1968; Kurien and Oliver, 1970).

Linoleic acid has been shown as having antiarrhythmic potencies, leading to a protective effect against pharmacologically-induced cardiac arrhythmias (Mest, Blass and Förster, 1977).

\section{Mechanism of action of dietary fats on arterial thrombosis}

The findings discussed so far are only a small part of the evidence which indicates that saturated fats are pro-thrombic and that dietary linoleic acid has anti-thrombotic properties. Nonetheless, there is still no agreement that a diet low in saturated fats and enriched in linoleic acid would decrease the coronary risk. Unfortunately, it is highly unlikely that the final proof of such an effect will ever be produced, not only because 'numbers necessary to do a pure diet-heart trial are too large to attempt such a program' (Vogt, 1978), but especially since the vast amount of data indicating the beneficial effect of such a diet will prevent this trial from being accepted by any ethical committee.

Another convincing approach might therefore be to unravel the mechanisms by which the dietary fat type affects atherosclerosis, arterial thrombosis and-ultimately-platelet thrombotic functions. Apart from the composition of adipose tissue and plasma FFAs, discussed above, the thromboxane/ prostacyclin balance, platelet membrane fluidity and the coagulation response following blood-vessel wall interaction may be of importance in this respect.

The tendency to arterial thrombosis is now thought to depend on the ratio between prothrombotic thromboxane $A_{2}\left(T \times A_{2}\right)$ produced by activated blood platelets and antithrombotic prostaglandin $\mathrm{I}_{2}$ (prostacyclin, $\mathrm{PGI}_{2}$ ) formed in vascular tissue (Moncada and Vane, 1978). Both substances have the same precursor fatty acid, arachidonic acid, which is mainly synthesized in the body from dietary linoleic acid. Therefore, it is tempting to speculate that the anti-thrombotic effect of oils rich in linoleic acid is mediated by a change of this thromboxaneprostacyclin balance towards a less thrombogenic state. However, this appeared not to be so: although a high linoleic acid diet increases the obstruction time in rats significantly as compared to a low linoleic acid or a high saturated fat diet (and consequently lowers the tendency to arterial thrombosis), production of platelet $\mathrm{TxA}_{2}$ (measured as its metabolite malondialdehyde) and of vascular prostacyclin is hardly affected.

However, the thromboxane-prostacyclin concept might be an oversimplification of the thromboregulatory mechanism because other prostaglandins are formed as well, some of which $\left(\mathrm{PGE}_{1}, \mathrm{PGD}_{2}\right)$ have distinct anti-aggregation effects on blood platelets (Kloeze, 1967; Smith, Silver and Ingerman, 1974). This might be the more important since feeding increasing amounts of linoleic acid to rat and man causes the urinary excretion of prostaglandin $\mathrm{E}$ and $\mathrm{F}$ metabolites to increase proportionally (Zöllner, Adam and Wolfram, 1979; Nugteren et al., 1980).

Moreover, replacement of dietary saturated fatty acids by linoleic acid has been shown to result in an increased prostaglandin production of stimulated rat adipocytes (Lipinski and Mathias, 1978), and of an enhanced prostaglandin synthetic potential of rat whole lung (Meydani, Mathias and Schatte, 1978).

Platelet plasma membranes-like all other mammalian plasma membranes-are mainly composed of a phospholipid bilayer, free cholesterol and proteins (Singer and Nicolson, 1972). These membranes have a certain fluidity which is essential for their function (Sinha, Shattil and Colman, 1977). A major determinant of membrane fluidity is the molar ratio between the membrane-free cholesterol and phospholipid content (C/P ratio) (Vanderkooi et al., 1974; Shattil and Cooper, 1976; Demel and de Kruijff 1976). Following an increase in their C/P ratio in vitro (causing an enhanced membrane fluidity) the aggregation tendency of platelets increases (Shattil et al., 1975), as does platelet thromboxane production in response to thrombin (Stuart, Gerrard and White, 1980). This indicates that membrane fluidity may affect platelet function. Indeed, platelets of patients suffering from type II ${ }^{a}$ hyperlipoproteinaemia showed an increased $\mathbf{C} / \mathbf{P}$ ratio (Shattil et al., 1977) and were hypersensitive towards activation (Carvalho, Colman and Lees, 1974; Shattil et al., 1977; Tremoli et al., 1979a, b). In rats, the dietary fat type may be able to modify platelet $\mathrm{C} / \mathrm{P}$ ratio (Hornstra, 1975). Moreover, it determines platelet phospholipid fatty acid composition (Renaud et al., 1970; Nordøy and Rødset, 1971; Hornstra, 1975) which is also implicated in membrane fluidity (Shinitzky and Barenholz, 1978). Therefore, the type of dietary fat might be able to modify platelet membrane fluidity. Recently, preliminary results have been reported which confirm. this suggestion (Berlin and Young, 1979) but further experiments are needed to demonstrate that this mechanism is involved in dietary fat-induced changes in platelet function and thrombosis.

Injured vascular tissue has thromboplastic activity, as a result of which vascular damage triggers blood clotting. Thrombin generated as a result of this clotting response is of key importance in platelet aggregation following vascular injury (Hornstra and Hemker, 1979). Vessel wall-induced clotting can 
be influenced by the type of dietary fat. After feeding rats diets containing sunflower seed oil, linseed oil or hydrogenated coconut oil, a striking relationship was observed between the tendency to arterial thrombosis and vessel wall-induced clotting. This indicates that the clotting response may contribute to arterial thrombus formation. One of the determinants of vessel wall-induced clotting is the clot-promoting effect of the blood platelets (Walsh, 1974; Hornstra and Hemker, 1979). In extensive series of experiments it has been shown that the type of dietary fat greatly influences platelet clot-promoting activity in rats and rabbits (Renaud and Gautheron, 1973/74, 1975; Tremoli, 1977). In humans, an increased risk for coronary thrombosis coincides with an enhanced clot-promoting effect of the platelets (Renaud et al., 1979). This platelet hyper-reactivity was shown to return to normal simply by replacing butter, cream and milk with 'soft' margarines, vegetable oils and low fat milk. These findings may present an explanation for the effect of linoleic acid-rich oils in lowering the tendency to thrombosis.

\section{Fish oils and arterial thrombosis}

Based on epidemiological studies in Greenland Eskimoes, Dyerberg and his colleagues advocated dietary enrichment with PFAs present in fish oils, especially with eicosapentaenoic acid (EPA). This fatty acid is the precursor of the 3-series prostaglandins of which platelet $\mathrm{TxA}_{3}$ has only weak prothrombotic properties; whereas $\mathrm{PGI}_{3}$, possibly produced in the vascular wall, is an antithrombotic substance as active as prostacyclin. Therefore, these workers suggested that, apart from its blood lipid-lowering effect, EPA might retard the development of atherosclerosis by changing the thromboxane-prostacyclin balance towards a less thrombogenic state (Dyerberg et al., 1978; Dyerberg and Bang, 1979).

The present author indeed confirmed the antithrombotic effect of cod liver oil in rats, which appeared to coincide with a highly reduced production of platelet thromboxanes. However, vascular prostacyclin formation was reduced to the same extent, whereas $\mathrm{PGI}_{3}$ was not formed in measurable amounts. These findings could be explained on the basis of the fatty acid spectra of platelet and vessel wall phospholipids as well as by the fact that EPA is a poor substrate for prostaglandin-producing enzymes (Hornstra, Haddeman and ten Hoor, 1979). It should be noted that not all marine oils have the same anti-thrombotic potency as cod liver oil. Whale oil, for instance, is slightly thrombogenic (Hornstra and Lussenburg, 1975) whereas a Peruvian fish oil had an intermediate effect (personal observation). Moreover, it should be stressed that cod liver oil has been shown to prolong the bleeding time in $\frac{3}{\mathrm{D}}$ rats (Hornstra et al., unpublished observation); this is in accord with findings in Greenland Eskimoes by Dyerberg and Bang (1979) but, in fact, may present a pathological condition. Ingestion of marine oils has also been shown to cause cardiac necrosis, induced by subtoxic levels of noradrenaline (Gudbjarnason and Hallgrimsson, 1976; Gudbjarnason, 1980). Moreover, a relatively large intake of fish oils is held responsible for yellow fat disease, a generalized disorder of fatty depots observed in a wide variety of animal species (Ruiter et al., 1978). Therefore, it seems premature to advocate a general dietary use of these oils.

\section{Concluding remarks}

After the onset of myocardial infarction about $50 \%$ of patients die within a few hours, leaving too little time for successful intervention and/or secondary prevention. This implies that primary prevention of coronary disease is of major importance. CHD results from atherosclerosis of the coronary arteries. Blood platelets have been shown to contribute to genesis, course and complications of the atherosclerotic process. Therefore, lowering enhanced platelet reactivity should be one of the objectives of primary prevention. One of the possibilities or achieving this goal is to change the dietary como position. Based on experimental studies in animals and man, partly discussed here, a decreased intake of saturated fatty acids is recommended together with an increased consumption of polyunsaturated fatty acids, especially of the linoleic acid family. In practice, this means an enhanced intake of linoleic acid-rich products. This would not only lower the tendency to arterial thrombosis, but other atherosclerosis risk factors as well, since linoleic acid has been shown to decrease serum cholesterol, especially LDL cholesterol, to lower 'borderline' hypertension and to normalize biochemical abnormalities in obesity and maturity onset diabetes. Moreover, animal studies clearly indicate that a linoleic acid-rich diet improves cardiac perfusion and work capacity (Vergroesen et al., 1980).

Finally, no major adverse effect of dietary linoleic acid has ever been reported which, on careful screening of the data, could not be dismissed (Heyden, 1975). It is agreed that conclusive proof of the efficacy of the recommended dietary changes on the morbidity and mortality of atherosclerosis is difficult, if not impossible, to get. However, the experimental evidence already available does not allow any further delay in initiating these changes. Moreover, research must go on, especially into the mechanisms by which dietary changes affect the atherosclerotic processes. 


\section{References}

Berlin, E. \& Young, C. (1979) Effects of dietary fat on the fluidity of platelet membranes. Biophysical Journal, 25, 64a.

Carvalho, A.C.A., Colman, R.W. \& Lees, R.S. (1974) Platelet function in hyperlipoproteinemia. New England Journal of Medicine, 290, 434.

ConNor, W.E., HoAk, J.C. \& Warner, E.D. (1969) Plasma free fatty acids, hypercoagulability and thrombosis. In: Thrombosis (Ed by Sherry, S., Brinkhous, K.M., Genton, E. and Stengle, J.M.), pp. 355-373. National Academy of Sciences, Washington D.C.

DAyton, S. (1966) Composition of lipids in human serum and adipose tissue during prolonged feeding of a diet high in unsaturated fat. Journal of Lipid Research, 7, 103.

Dayton, S., Pearce, M.L., Hashimoto, S. \& Dixon, W.J. (1969) A controlled clinical trial of a diet high in unsaturated fat: in preventing complications of atherosclerosis. Circulation, 40 (Suppl. 2), 1-63.

Demel, R.A. \& DE KRuiJfF, B. (1976) The function of sterols in membranes. Biochimica et biophysica acta, 457, 109.

Duguid, J.B. (1946) Thrombosis as a factor in the pathogenesis of coronary atherosclerosis. American Journal of Pathology and Bacteriology, 58, 207.

DYerberG, J. \& BANG, H.O. (1979) Haemostatic function and platelet polyunsaturated fatty acids in Eskimos. Lancet, ii, 433.

Dyerberg, J., Bang, H.O., Stoffersen, E., Moncada, S. \& VANE, J.R. (1978) Eicosapentaenoic acid and prevention of thrombosis and atherosclerosis. Lancet, ii, 117.

Fleischman, A.I., Hayton, T. \& Bierenbaum, M.L. (1967) Objective biochemical determination of dietary adherence in the young coronary male. American Journal of Clinical Nutrition, 20, 333.

Friedman, R.J., Stemerman, M.B., Wenz, B., Moore, S., Gauldie, J., Gent, M., Tiell, M.L. \& Spaet, T.H. (1977) The effect of thrombocytopenia on experimental arteriosclerotic lesion formation in rabbits. Smooth muscle cell proliferation and re-endothelialization. Journal of Clinical Investigation, 60, 1191.

Fuster, V. \& BowIE, E.J.W. (1978) The von Willebrand pig as a model for atherosclerosis research. Thrombosis and Haemostasis, 39, 322.

Gottenbos, J.J. \& Thomasson, H.J. (1961) Aorta atheromatosis in rabbits on feeding cholesterol or fats. Colloques internationaux du Centre national de la recherche scientifique, 99, 221

Gudbuarnason, S. (1980) Pathophysiology of long chain polyene fatty acids in heart muscle. Nutrition and Metabolism. Suppl. I. (In press.)

Gudbuarnason, S. \& Hallgrimsson, J. (1976) The role of myocardial membrane lipids in the development of cardiac necrosis. Acta medica scandinavica, 587 (Suppl.), 17.

Haerem, J.W. (1974) Platelet aggregation and mural microthrombi in early stages of acute fatal coronary disease. Thrombosis Research, 5, 243.

Harker, L.A., Ross, R., Slichter, S.J. \& Scott, C.R. (1976) Homocystine-induced arteriosclerosis. The role of endothelial cell injury and platelet response in its genesis. Journal of Clinical Investigation, 58, 731.

Harland, W.A. \& Holburn, A.M. (1966) Coronary thrombosis and myocardial infarction. Lancet, ii, 1158.

HEYDEN, S. (1975) Epidemiological data on dietary fat intake and atherosclerosis with an appendix on possible side effects. In: The Role of Fats in Human Nutrition. (Ed. by Vergroesen, A.J.), pp. 44-113. Academic Press, London, New York, San Francisco.

Hoak, J.C., Poole, J.C.F. \& Robinson, D.S. (1963) Thrombosis associated with mobilization of fatty acids. American Journal of Pathology, 43, 987.

HoAk, J.C., Spector, A.A., Fry, G.L. \& WARner, E.D.
(1970) Effect of free fatty acids on ADP-induced platelet aggregation. Nature. London, 228, 1330.

HoRnSTRA, G. (1973/74) Dietary fats and arterial thrombosis. Haemostasis, 2, 21.

HoRnStRa, G. (1975) Specific effects of types of dietary fat on arterial thrombosis. In: The Role of Fats in Human Nutrition (Ed by Vergroesen, A.J.), pp. 303-330. Academic Press, London, New York, San Francisco.

Hornstra, G. (1978) The filtragometer in thrombosis research. In: Platelet Function Testing (Ed by Day, H.J., Holmsen, H. and Zucker, M.B.), pp. 416-427. DHEW Publ. No. (NIH) 78-1087. U.S. Department of Health, Education and Welfare. Public Health Service, National Institute of Health.

Hornstra, G., Haddeman, E. \& Ten Hoor, F. (1979) Fish oils, prostaglandins and arterial thrombosis. Lancet, ii, 1080.

Hornstra, G. \& Hemker, H.C. (1979) Clot-promoting effect of platelet-vessel wall interaction; influence of dietary fats in relation to arterial thrombus formation. Haemostasis, 8, 211.

Hornstra, G., Lewis, B., Chait, A., Turpeinen, O., Karvonen, M.J. \& Vergroesen, A.J. (1973) Influence of dietary fat on platelet function in man. Lancet, $\mathbf{i}, 1155$.

Hornstra, G. \& Lussenburg, R.N. (1975) Relationship between the type of dietary fatty acid and arterial thrombosis tendency in rats. Atherosclerosis, 22, 499.

HoRnstra, G. \& TEN HOOR, F. (1975) The filtragometer: a new device for measuring platelet aggregation in venous blood of man. Thrombosis et diathesis haemorrhagica, 34, 531.

Hornstra, G. \& Vendelmans-Starrenburg, A. (1973) Induction of experimental arterial occlusive thrombi in rats. Atherosclerosis, 17, 369.

KLOEZE, J. (1967) Influence of prostaglandins on platelet adhesiveness and platelet aggregation. In: Prostaglandins (Ed by Bergström, S. \& Samuelsson, B.), pp. 241-252. Almqvist and Wiksell, Stockholm.

Kostis, J.B., Mavrogeorgis, E.A., Horstmann, E. \& GotzoyanNis, S. (1973) Effect of high concentrations of free fatty acids on the ventricular fibrillation threshold in normal dogs and dogs with acute myocardial infarction. Cardiology, 58, 89.

Kurien, V.A. \& Oliver, M.F. (1970) A metabolic cause for arrhythmias during acute myocardial infarction. Lancet, i, 813.

Leren, P. (1970) The Oslo diet-heart study. Circulation, 42, 935.

Lipinski, B.A. \& Mathias, M.M. (1978) Prostaglandin production and lipolysis in isolated rat adipocytes as affected by dietary fat. Prostaglandins, 16, 957.

Logan, R.L., Thomson, M., Riemersma, R.A., Oliver, M.F., Olsson, A.G., Rössner, S., Callmer, E., Walldius, G., Kaijser, L., Carlson, L.A., Lockerbie, L. \& Lutz, W. (1978) Risk factors for ischaemic heart disease in normal men aged 40. Edinburgh-Stockholm study. Lancet, i, 949.

Malmros, H. (1969) Dietary prevention of atherosclerosis. Lancet, ii, 479.

Mest, H.J., Blass, K.E. \& Förster, W. (1977) Effects of arachidonic, linoleic, linolenic and oleic acid on experimental arrhythmias in cats, rabbits and guinea-pigs. Prostaglandins, 14, 163.

Meydani, S.N., Mathias, M.M. \& Schatte, C.L. (1978) Dietary fat type and ambient oxygen tension influence pulmonary prostaglandin synthetic potential. Prostaglandins and Medicine, 1, 241.

Miettinen, M., Turpeinen, O., Karvonen, M.J., Elosuo, R. \& PaAvilainen, E. (1972) Effect of cholesterol-lowering diet on mortality from coronary heart disease and other causes: a twelve-year clinical trial in men and women. Lancet, ii, 835. 
MoncadA, S. \& VANE, J.R. (1978) Unstable metabolites of arachidonic acid and their role in haemostasis and thrombosis. British Medical Bulletin, 34, 129.

MOORE, S. (1974) Thrombosis and atherosclerosis. Thrombosis et diathesis haemorrhagica, 60 (Suppl.), 205.

Moore, S., Friedman, R.J., Singal, D.P., Gauldie, J. \& BLAJCHMAN, M. (1976) Inhibition of injury-induced thrombo-atherosclerotic lesions by anti-platelet serum in rabbits. Thrombosis et diathesis haemorrhagica, 35, 70.

MUSTARD, J.F. \& PACKHAM, M.A. (1970) Factors influencing platelet function: adhesion, release and aggregation. Pharmacological Reviews, 22, 97.

NoRDøY, A. \& RøDSET, J.M. (1971) The influence of dietary fats on platelets in man. Acta medica scandinavica, 190, 27.

Nugteren, D.H., van Evert, W.C., Soeting, W.J. \& Spuy, J.H. (1980) The effect of different amounts of linoleic acid in the diet on the excretion of urinary prostaglandin metabolites in the rat. Advances in Prostaglandin and Thromboxane Research, 1, 1793.

Oliver, M.F., Kurien, V.A. \& GreenWoOd, T.W. (1968) Relation between serum free fatty acids and arrhythmias and death after acute myocardial infarction. Lancet, i, 710.

OPIE, L.H., NorRIS, R.M., ThOmas, M., Holland, A.J., OWen, P. \& VAN NOORTEN, S. (1971) Failure of high concentration of circulating free fatty acids to provoke arrhythmias in experimental myocardial infarction. Lancet, i, 818.

OWREN, P. (1964) Nutrition and thrombosing atherosclerosis. Bibliotheca nutritio et dieta, 6, 156.

Prost-Dvojakovic, R.J. \& Samama, M. (1973/74) Clot promoting and platelet-aggregating effects of fatty acids. Haemostasis, $2,73$.

Renaud, S. \& Gautheron, P. (1973/74) Dietary fats and experimental (cardiac and venous) thrombosis. Haemostasis, $2,53$.

Renaud, S. \& Gautheron, P. (1975) Influence of dietary fats on atherosclerosis, coagulation and platelet phospholipids in rabbits. Atherosclerosis, 21, 115.

Renaud, S., Kuba, K., Goulet, C., Lemire, Y. \& Allard, C. (1970) Relationship between fatty acid composition of platelets and platelet aggregation in rat and man. Relation to thrombosis. Circulation Research, 26, 553.

Renaud, S., Morazain, R., McGregor, L. \& Baudier, F. (1979) Dietary fats and platelet functions in relation to atherosclerosis and coronary heart disease. Haemostasis, 8, 234

Ross, R. \& Glomset, J.A. (1976) The pathogenesis of atherosclerosis. New England Journal of Medicine, 295, 369, 420.

Ross, R., Glomset, J.A., KARIYA, B. \& HARKeR, L.A. (1974) A platelet-dependent serum factor that stimulates the proliferation of arterial smooth muscle cells in vitro. Proceedings of the National Academy of Sciences of the United States of America, 71, 1207.

Ruiter, A., Jongbloed, A.W., van Gent, C.M., Danse, L.H.J.C. \& METZ, S.H.M. (1978) The influence of dietary mackerel oil on the condition of organs and on blood lipid composition in young growing pigs. American Journal of Clinical Nutrition, 31, 2159.

Shattil, S.J., Anaya-Galindo, R., Bennett, J., Colman, R.W. \& COOPER, R.A. (1975) Platelet hypersensitivity induced by cholesterol incorporation. Journal of Clinical Investigation, 55, 636 .

Shattil, S.J., Bennett, J.S., Colman, R.W. \& Cooper, R.A. (1977) Abnormalities of cholesterol-phospholipid composition in platelets and low-density lipoproteins of human hyperbetalipoproteinemia. Journal of Laboratory and Clinical Medicine, 89, 341.

ShatTIL, S.J. \& CoOPER, R.A. (1976) Membrane microviscosity and human platelet function. Biochemistry, 15, $\overrightarrow{\overline{\vec{S}}}$ 4832.

Shimamoto, T. (1974) Contraction of endothelial cells as a key mechanism in atherogenesis and treatment of atherosclerosis with endothelial cell relaxants. In: Atherosclerosis $\overline{\bar{D}}$ III (Ed. by Schettler, G. \& Weizel, A.), pp. 64-82. Springer Verlag, Berlin, Heidelberg, New York.

ShINITZKY, M. \& BARENHOLZ, Y. (1978) Fluidity parameters of lipid regions determined by fluorescence polarization. Biochimica et biophysica acta, 515, 367.

SINAPIUS, D. (1972) Beziehungen zwischen Koronarthrombosen und Myokardinfarkten. Deutsche medizinische $\vec{\omega}$ Wochenschrift, $97,443$.

Singer, S.J. \& Nicolson, G.L. (1972) The fluid mosaic model of the structure of cell membranes. Science, 175, 720.

Sinha, A.K., Shattil, S.J. \& Colman, R.W. (1977) Cyclic AMP metabolism in cholesterol-rich platelets. Journal of $\mathcal{G}$ Biological Chemistry, 252, 3310.

SMITH, J.B., Silver, M.J. \& INGERMaN, C.M. (1974) Prosta- U glandin $\mathrm{D}_{2}$ inhibits the aggregation of human platelets. Thrombosis Research, 5, 291.

STAMLER, J. (1973) Epidemiology of coronary heart disease. Medical Clinics of North America, 57, 5.

StuarT, M.J., Gerrard, J.M. \& White, J.G. (1980) Effect of cholesterol on production of thromboxane $B_{2}$ by platelets in vitro. New England Journal of Medicine, 302, 6.

Sumiyoshi, A., More, R.H. \& WeIGensBerg, B.I. (1973) Aortic fibrofatty type atherosclerosis from thrombus in 9 normolipidemic rabbits. Atherosclerosis, 18, 43.

Tremol, E. (1977) Washed guinea-pig and rat platelets posse factor X activator activity. British Journal of Haematolog 37, 155.

Tremoli, E., Folco, G., Agradi, E. \& Galli, C. (1979 Platelet thromboxanes and serum cholesterol. Lancet, i, 107.

Tremoli, E., Maderna, P, Sirtori, M. \& Sirtori, C.R. (1979b) Platelet aggregation and malondialdehyde formation in type IIA hypercholesterolemic patients. Haemostasis, 8, 47.

Vanderkooi, J., Fischkoff, S., Chance, B. \& Cooper, R.A. (1974) Fluorescent probe analysis of the lipid architecture of natural and experimental cholesterol-rich membranes. Biochemistry, 13, 1589.

Vergroesen, A.J., De Deckere, E.A.M., TEN Hoor, F. \& HORNSTRA, G. (1980) Cardiovascular effects of linoleic acid. In: Proceedings of the Round Table on Polyunsaturated Fatty Acids in Nutrition. (Ed. by Galli, C. \& Galli, M.). (In press.) Pergamon Press Ltd., Oxford.

Vles, R.O., Büller, J., GotTenbos, J.J. \& Thomasson, H.J. (1964) Influence of type of dietary fat on cholesterolinduced atherosclerosis in the rabbit. Journal of Atherosclerosis Research, 4, 170.

VoGT, T.M. (1978) Diet-heart era: premature obituary? New England Journal of Medicine, 298, 107.

WALSH, P. (1974) Platelet coagulant activities and hemostasis. A hypothesis. Blood, 43, 597.

WoLf, S. (Ed.) (1971) The artery in the process of arteriosclerosis. Pathogenesis. In: Advances in Experimental Medicine and Biology 16a, 1.

Zöllner, N., ADAM, O. \& Wolfram, G. (1979) The influence of linoleic acid intake on the excretion of urinary prostaglandin metabolites. Research in Experimental Medicine, 175, 149. 